Research Article

\title{
Relationship between the Usage of Long-Lasting Insecticide-Treated Bed Nets (LLITNs) and Malaria Prevalence among School-Age Children in Southwestern Nigeria
}

\author{
Adejumoke Oluwatosin Omonijo ${ }^{D},{ }^{1}$ Adetunji Omonijo ${ }^{(D)},{ }^{2}$ Hillary Iwegbunem Okoh (D), \\ and Azeez Oyemomi Ibrahim $\mathbb{D}^{2}$
}

${ }^{1}$ Department of Animal and Environmental Biology, Federal University Oye Ekiti State, Oye Ekiti, Nigeria

${ }^{2}$ Department of Family Medicine, Federal Teaching Hospital, Ido Ekiti, Ekiti State, Nigeria

Correspondence should be addressed to Adejumoke Oluwatosin Omonijo; earnesthope@yahoo.com

Received 29 September 2020; Revised 12 February 2021; Accepted 3 March 2021; Published 26 March 2021

Academic Editor: Arun S. Kharat

Copyright (c) 2021 Adejumoke Oluwatosin Omonijo et al. This is an open access article distributed under the Creative Commons Attribution License, which permits unrestricted use, distribution, and reproduction in any medium, provided the original work is properly cited.

\begin{abstract}
Purpose. The usage of LLITNs in malaria vector control has resulted in the reduction in malaria deaths among higher-risk groups (pregnant women and under-fives). However, there exists asymptomatic infection among older children, thereby making them a reservoir of malaria transmission. This study aimed at assessing the impact of LLITN usage on malaria prevalence among schoolage children (SAC) in Ekiti, South Western Nigeria. Methods. Cross-sectional, two-stage cluster sampling technique was used to collect data from SAC during May and June 2017. A total of 1313 (Oye LGA: 657 and Ikole LGA: 656) SAC in selected public primary schools participated in the study. Sociodemographic information as well as data on LLITN usage the previous night was obtained using pretested, semistructured questionnaires adapted from the standardized Malaria Indicator Survey (MIS) tools. Malaria infection was diagnosed by using the rapid diagnostic test (RDT) on blood samples that were collected by finger prick from each child. Data were analyzed using the Statistical Package for Social Sciences (SPSS) for Windows software version 26 (SPSS Inc., Chicago, IL, USA). Results. Usage of LLITNs among SAC was significantly higher in Ikole LGA than in Oye $(p<0.001)$. Socioeconomic factors (access to electricity, mother's occupation, and household size) showed significant associations with LLITN usage $(p<0.001)$ in both Oye and Ikole LGAs. Malaria prevalence was significantly low among SAC utilizing LLITNs in both Oye and Ikole LGAs $(p<0.001)$. There was a significant association between gender and malaria prevalence among SAC with males having higher prevalence than females $(p<0.001)$. Socioeconomic factors were significantly associated with malaria prevalence in both LGAs $(p<0.001)$. Conclusion. The usage of LLITNs caused a significant reduction in malaria prevalence among the school-age children in the study areas; hence, sensitization on usage should be scaled up towards malaria elimination.
\end{abstract}

\section{Introduction}

Malaria is a leading cause of morbidity and mortality most especially among vulnerable groups in sub-Saharan Africa. An estimated 228 million cases of malaria occurred worldwide (95\% confidence interval (CI): 206-258 million), with $93 \%$ of the cases occurring in the World Health Organization (WHO) African Region. Nigeria constitutes one of the six countries that account for more than half of all malaria cases worldwide [1]. While deliberate efforts have resulted in the reduction of malaria deaths, mainly among higher risk groups, the epidemiology and management of malaria in school-age children have received little attention until recently $[1,2]$. Studies have shown that reduction in the level of malaria transmission in endemic areas causes gradual immunity acquisition to malaria among older children and adults, thereby making them transmission reservoirs [3, 4]. Recent studies revealed the burden of malaria in school-age children, their role in acting as a reservoir of infection, and the least likelihood of SAC in utilizing insecticide-treated nets (ITNs) [4-6]. 
The effectiveness of LLITNs in malaria control and the role of schools have been demonstrated [7-11]. While earlier studies have surveyed LLITN usage among school children and school-based net distribution in the integrated national malaria surveillance system $[5,12]$, there is a paucity of information on the impact of LLITN usage on malaria prevalence among school-age children in Nigeria. This study aims to assess the level of usage of LLITNs and its impact on malaria prevalence among school-age children in Ekiti Southwestern State, Nigeria, with the hope of incorporating the outcome into malaria interventions capable of increasing and sustaining net usage among the study group.

\section{Materials and Methods}

2.1. Study Area. The study was carried out among school-age children in Oye and Ikole local government areas (LGAs) in Ekiti State. The State is in one of the three major malaria epidemiological zones in Nigeria and is characterized by a tropical climate with an alternating rainy season (April-October) and dry season (November-March). Temperature ranges between $21^{\circ} \mathrm{C}$ and $28^{\circ} \mathrm{C}$ with high humidity, all favourable to malaria vector development.

2.2. Sample Size Calculation. Sample size was calculated using the equation $n=1.96^{2} \mathrm{pq} / \mathrm{L}^{2}$, where $n=$ sample size, $p=$ expected prevalence $(0.5), q=1-\mathrm{p}(1-0.5)$, and $L=$ limit.

2.3. Study Design. A community-based cross-sectional design was used in this study. For this study, only public, mixed primary schools were selected. The study flowchart is shown in Figure 1. Two-stage cluster sampling technique was used given the large size of the study area and based on the availability of resources at the time of the study. Each LGA was divided into geographical clusters of north, east, west, and south. Two to three (2-3) primary schools were then selected from a line list of all primary schools in each of the four (4) clusters using a simple random sampling technique. A total of ten (10) primary schools were selected from the four (4) clusters in each LGA. Simple random sampling technique was then used in selecting 714 and 710 school-age children from Oye and Ikole LGAs, respectively, and out of which 657 and 656 school-age children met the inclusion and exclusion criteria. Finally, a total of 1313 participants from the two (2) LGAs were used for this study (Figure 1).

\subsection{Data Collection}

2.4.1. Data on Malaria Survey. Malaria infection in SAC was diagnosed by using the rapid diagnostic test (RDT) on blood samples that were collected by finger prick from each child. This was conducted and recorded by trained health personnel. The RDTs were the CareStart ${ }^{\circledR} \mathrm{Pf} / \mathrm{Pv}$ combo test (Access Bio, Inc., Somerset, NJ, USA), containing an alcohol swab, lancet, capillary tube, buffer, and test device.
2.4.2. Questionnaire Administration. A total of 1313 (Oye LGA: 657 and Ikole LGA: 656) semistructured interviewerguided questionnaires were administered to school-age children who met the inclusion and exclusion criteria in selected primary schools. Sociodemographic information, as well as data on LLITN usage the previous night, was obtained using pretested, semistructured questionnaires adapted from the standardized Malaria Indicator Survey (MIS) tools. Questionnaires were pretested in Ido/Osi local government area of Ekiti State and administered by trained interviewers comprising of fresh university graduates. Data collection occurred during the school term and lasted for two months during May and June 2017. The interviews were conducted in English and Yoruba languages. The interviewers were frequently supervised on the field by a designated team leader and researcher to monitor data collection and provide necessary feedback. Each respondent was interviewed for 20 minutes.

2.4.3. Data Analysis. Data were analyzed using the Statistical Package for Social Sciences (SPSS) for Windows software version 26 (SPSS Inc., Chicago, IL, USA). Frequency tables were generated for relevant variables, and percentages were determined as appropriate. Malaria prevalence was calculated by dividing the number of SAC that have positive RDT result by the total number of pupils that were tested from each LGA. Pearson's chi-square test was used to assess the bivariate association between usage of LLITNs and malaria prevalence. $p$ value of less than 0.001 was considered as statistically significant.

2.5. Ethical Approval and Consent. Approval for the study was obtained from the Ministry of Health, Ekiti State, $\mathrm{MOH} /$ PRS/15/137, Ekiti State Primary Education Board (SPEB), EKSUBEB/ADM/79/123, and Local Government Education Authority Executive Secretaries. Education officers from the district education office in the LGAs assisted the team in locating the schools. The headteacher and teachers at each school that were enrolled in the study were shown approval letters and were informed about the purpose of the study. Awareness and sensitization for the program were carried out through the Parent-Teacher Association (PTA) forum before the study. Only pupils whose parents consented to the study participated in the study.

\section{Results}

3.1. Sociodemographic Factors of Respondents. In total, 1313 school children participated in the study: 657 and 656 in selected primary schools in Oye and Ikole LGAs, respectively. The sociodemographic characteristics of the participants are shown in Table 1. Overall mean age was 9.5 2.3. Majority of respondent's mothers completed secondary education (65.3\% in Oye LGA; $62.5 \%$ in Ikole LGA) and were self-employed $(38.7 \%$ in Oye LGA; $60.8 \%$ in Ikole LGA). Majority were Christians ( $81.1 \%$ in Oye LGA and $85.4 \%$ in Ikole LGA), with Yoruba ethnicity (92.8\% in Oye LGA and $94.8 \%$ in Ikole LGA) with household size $\leq 4$ (54.5\% in Oye LGA and 64.3\% in Ikole LGA) constituting the majority of respondents in both LGAs (Table 1). 


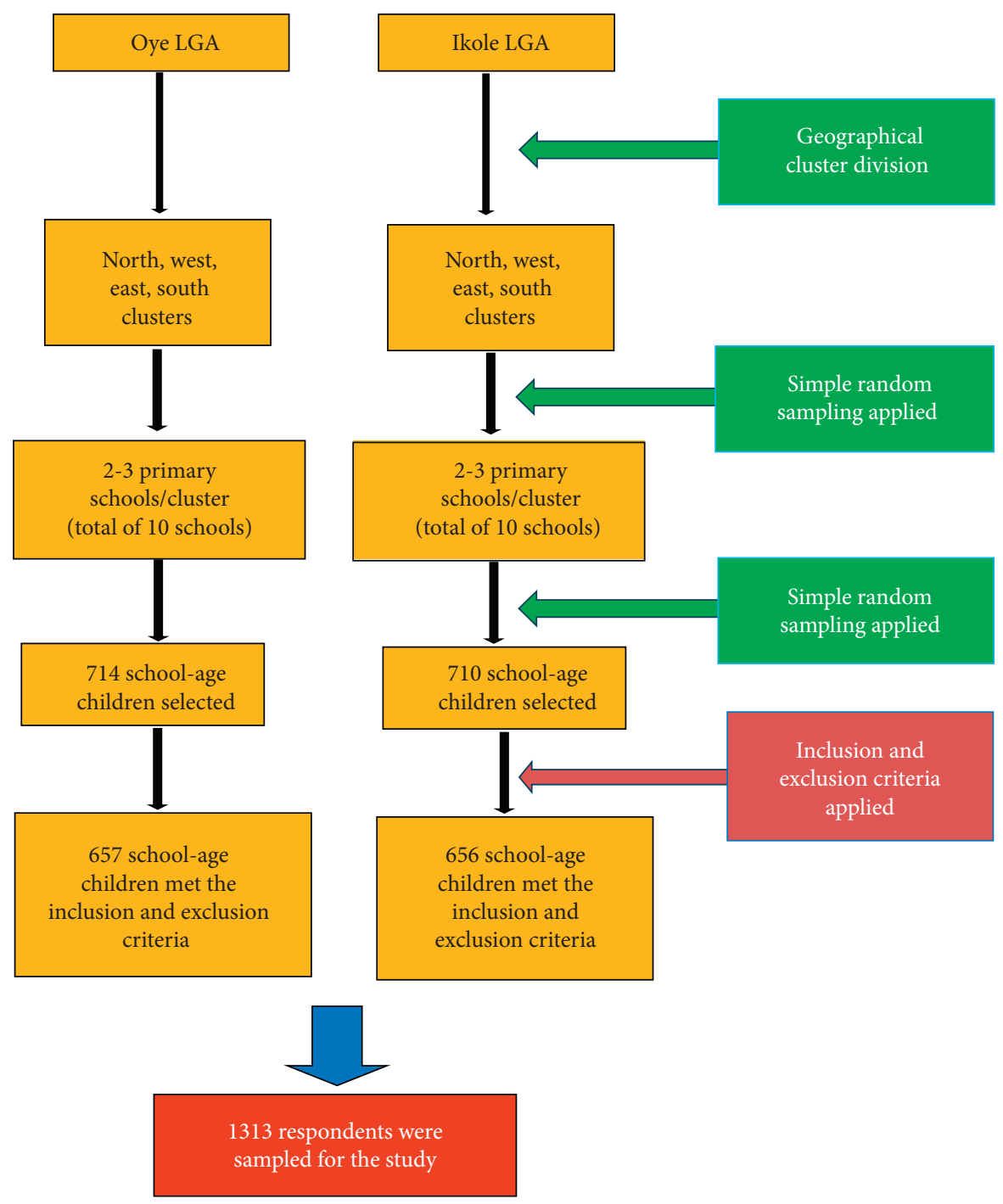

FIgURe 1: Study flowchart.

3.2. Assessment of the Level of Usage of LLITNs among SAC in Oye and Ikole LGAs. Usage of LLITNs was observed to be generally high in both Oye and Ikole LGAs and was estimated at $(79.9 \%)$ in Oye LGA and $(86.0 \%)$ in Ikole LGA, respectively. However, usage of LLITNs was significantly higher in Ikole than Oye LGA $(p<0.001)$ (Table 2).

\subsection{Association of Sociodemographic Characteristics with} Usage of LLITNs among SAC in Oye and Ikole LGAs. There was no significant difference between males and females with respect to the usage of LLITNs in the two LGAs. In Oye LGA ethnicity, household size and access to electricity were observed to have significant association with LLITN usage $(p<0.001)$, while in Ikole LGA, mother's education, mother's occupation, ethnicity, household size, and access to electricity were significantly associated with LLITN usage $(p<0.001)$ (Table 3$)$.
3.4. Association of Sociodemographic Characteristics with Malaria Prevalence among SAC in Oye and Ikole LGAs. Malaria prevalence in SAC was low in both Oye LGA (16.98\%) and Ikole LGA (16.83\%) (Figure 2). Sociodemographic factors such as mother's education, mother's occupation, household size, and access to electricity were significantly associated with malaria prevalence in both Oye and Ikole LGAs except in Ikole LGA where additionally, gender showed significance association with malaria prevalence (Table 4 ).

3.5. Relationship between LLITN Usage and Malaria Prevalence among SAC in Oye and Ikole LGAs. The association between LLITN usage and malaria prevalence among SAC in the two LGAs is shown in (Table 5). Our results showed that malaria prevalence was significantly lower among SAC that used LLITNs in both Oye and Ikole LGA $(p<0.001)$ (Table 5). 
TABLE 1: Sociodemographic characteristics of respondents.

\begin{tabular}{|c|c|c|c|}
\hline Variables & $\begin{array}{l}\text { Oye (\%) } \\
N=657\end{array}$ & $\begin{array}{c}\text { Ikole (\%) } \\
N=656\end{array}$ & $\begin{array}{l}\text { Total }(\%) \\
N=1313\end{array}$ \\
\hline Age (years) & & & $9.5 \pm 2.3$ \\
\hline $6-8$ & $244(37.1)$ & $246(37.5)$ & $490(37.3)$ \\
\hline $9-11$ & $246(37.4)$ & $238(36.3)$ & $484(36.9)$ \\
\hline$\geq 11$ & $167(25.5)$ & $172(26.2)$ & $339(25.8)$ \\
\hline \multicolumn{4}{|l|}{ Gender } \\
\hline Male & $336(51.1)$ & $351(53.5)$ & $687(52.3)$ \\
\hline Female & $321(48.9)$ & $305(46.5)$ & $626(47.7)$ \\
\hline \multicolumn{4}{|c|}{ Mother's education } \\
\hline Primary & $102(15.5)$ & $72(11.0)$ & $174(13.3)$ \\
\hline Secondary & $429(65.3)$ & $410(62.5)$ & $839(63.9)$ \\
\hline Tertiary & $126(19.2)$ & $174(26.5)$ & $300(22.8)$ \\
\hline \multicolumn{4}{|c|}{ Mother's occupation } \\
\hline Farmer & $69(10.5)$ & $29(4.4)$ & $98(7.5)$ \\
\hline Trader & $147(22.4)$ & $31(4.7)$ & $178(13.6)$ \\
\hline Self-employed & $254(38.7)$ & $399(60.8)$ & $653(49.7)$ \\
\hline Civil service & $168(25.6)$ & $197(30.0)$ & $365(27.8)$ \\
\hline Others & $19(2.9)$ & $0(0.0)$ & $19(1.4)$ \\
\hline \multicolumn{4}{|l|}{ Religion } \\
\hline Christian & $533(81.1)$ & $560(85.4)$ & $1093(83.2)$ \\
\hline Islam & $124(18.9)$ & $96(14.6)$ & $220(16.8)$ \\
\hline \multicolumn{4}{|l|}{ Ethnicity } \\
\hline Yoruba & $610(92.8)$ & $622(94.8)$ & $1232(93.8)$ \\
\hline Igbo & $37(5.6)$ & $25(3.8)$ & $62(4.7)$ \\
\hline Hausa & $10(1.5)$ & $9(1.4)$ & $19(1.5)$ \\
\hline \multicolumn{4}{|l|}{ Household size } \\
\hline$\leq 4$ & $358(54.5)$ & $422(64.3)$ & $780(59.4)$ \\
\hline$>4$ & $299(45.5)$ & $234(35.7)$ & $533(40.6)$ \\
\hline \multicolumn{4}{|c|}{ Access to electricity } \\
\hline Yes & $475(72.3)$ & $479(73.0)$ & $954(72.7)$ \\
\hline No & $182(27.7)$ & $177(27.0)$ & $359(27.3)$ \\
\hline
\end{tabular}

TABLE 2: Assessment of the level of usage of LLITNs among respondents.

\begin{tabular}{lccc}
\hline Variable & $\begin{array}{c}\text { Oye }(\%) \\
N=657\end{array}$ & $\begin{array}{c}\text { Ikole }(\%) \\
N=656\end{array}$ & $\begin{array}{c}\text { Total }(\%) \\
N=1313\end{array}$ \\
\hline Usage & & & \\
Yes & $525(79.9)$ & $564(86.0)$ & $1089(82.9)$ \\
No & $132(20.1)$ & $92(14.0)$ & $224(17.1)$ \\
$p$ value & & $\chi^{2}=8.539,(p<0.001)$ & \\
\hline
\end{tabular}

\section{Discussion}

Vector control through LLITNs constitutes one of the effective control measures in reducing deaths due to malaria [1]. This study aimed at assessing the relationship between the usage of LLITNs and malaria prevalence among school-age children (SAC) in Oye and Ikole LGAs. The findings from this study revealed that the usage of LLITNs was generally high in both LGAs. The rate of LLITN usage observed among SAC in this study is higher in Oye LGA (79.9\%) and Ikole LGA (86.0\%) than the available record in Kenya, Malawi, and other regions $[9,12-15]$. It is, however, lower than the level of usage $(88.8 \%)$ found in a study in Ibadan [11]. This may be because of the lower age range of most of the respondents
(6-8 years) observed in this study as compared with the age range of most of the respondents (10-13 years) found in Ibadan [11]. Studies have shown that higher age increases better reportage [11].

The significant association between household size and LLITN usage observed in this study is consistent with reports from other studies from Ethiopia and Kenya [16-21] where LLITN usage was reportedly high in less household's size than larger household's size. This may be attributed to limited sleeping space in larger households $[16,22]$. On the contrary, no significant association was found between LLITN usage and household size in Burkina Faso [23].

Furthermore, the significant association between access to electricity and LLITN usage is consistent with reports from Ethiopia and Tanzania [24, 25]; however, this contradicts another study from South Ethiopia [21].

With regard to mother's education, finding from this study showed that mothers of SAC with secondary education utilized LLITNs in Ikole LGA more than those with primary education. This is consistent with another study from elsewhere [21]. Study has emphasized the role of maternal education in LLITN usage and combating malaria prevalence generally [21]; however, another study found no association [25]. 
TABLE 3: Association of sociodemographic characteristics with usage of LLITNs in Oye and Ikole LGAs.

\begin{tabular}{|c|c|c|c|c|c|c|}
\hline \multirow{3}{*}{ Variables } & \multicolumn{6}{|c|}{ Usage } \\
\hline & \multicolumn{3}{|c|}{ Oye $(\%)$} & \multicolumn{3}{|c|}{ Ikole (\%) } \\
\hline & Yes $n=525$ & No $n=132$ & Total $N=657$ & Yes $n=564$ & No $n=92$ & Total $=656$ \\
\hline \multicolumn{7}{|l|}{ Age } \\
\hline $6-8$ & $199(30.3)$ & $45(6.8)$ & $244(37.1)$ & $212(32.3)$ & $34(5.2)$ & $246(37.5)$ \\
\hline $9-11$ & $193(29.4)$ & $53(8.1)$ & $246(37.4)$ & $201(30.6)$ & $37(5.60$ & $238(36.3)$ \\
\hline$>11$ & $133(20.2)$ & $34(5.2)$ & $167(25.4)$ & $151(23.0)$ & $21(3.2)$ & $172(26.2)$ \\
\hline & \multicolumn{3}{|c|}{$\chi^{2}=0.744, p>0.001$} & \multicolumn{3}{|c|}{$\chi^{2}=0.936, p>0.001$} \\
\hline \multicolumn{7}{|l|}{ Gender } \\
\hline Male & $270(41.1)$ & $66(10.0)$ & $336(51.1)$ & $307(46.8)$ & $44(6.7)$ & $351(53.5)$ \\
\hline \multirow[t]{2}{*}{ Female } & $255(38.8)$ & $66(10.0)$ & $321(48.9)$ & $257(39.2)$ & $48(7.3)$ & $305(46.5)$ \\
\hline & \multicolumn{3}{|c|}{$\chi=0.086, p>0.001$} & \multicolumn{3}{|c|}{$\chi^{2}=1.388, p>0.001$} \\
\hline \multicolumn{7}{|c|}{ Mother's education } \\
\hline Primary & $81(12.3)$ & $21(3.2)$ & $102(15.5)$ & $65(9.9)$ & $7(1.1)$ & $72(11.0)$ \\
\hline Secondary & $351(53.4)$ & 78 (11.9) & $429(65.3)$ & $361(55.0)$ & $49(7.5)$ & $410(62.5)$ \\
\hline Tertiary & $93(14.2)$ & $33(5.0)$ & $126(19.2)$ & $138(21.1)$ & $36(5.5)$ & $174(26.5)$ \\
\hline & \multicolumn{3}{|c|}{$\chi^{2}=3.909, p>0.001$} & \multicolumn{3}{|c|}{$\chi^{2}=8.978, p<0.001$} \\
\hline \multicolumn{7}{|c|}{ Mother's occupation } \\
\hline Farmer & $59(9.0)$ & $10(1.5)$ & $69(10.5)$ & $25(3.8)$ & $4(0.6)$ & $29(4.4)$ \\
\hline Trader & $119(18.1)$ & $28(4.3)$ & $147(22.4)$ & $29(4.4)$ & $2(0.3)$ & $31(4.7)$ \\
\hline Self-employed & $205(31.2)$ & $49(7.5)$ & $254(38.7)$ & $354(54)$ & $45(6.9)$ & $399(60.8)$ \\
\hline Civil service & $127(19.3)$ & $41(6.2)$ & $168(25.6)$ & $156(23.8)$ & $41(6.3)$ & $197(30.0)$ \\
\hline Others & $15(2.3)$ & $4(0.6)$ & $19(2.9)$ & $0(0.0)$ & $0(0.0)$ & \\
\hline & \multicolumn{3}{|c|}{$\chi^{2}=3.506^{\ddagger}, p>0.001$} & \multicolumn{3}{|c|}{$\chi^{2}=11.499^{\ddagger}, p<0.001$} \\
\hline \multicolumn{7}{|l|}{ Religion } \\
\hline Christianity & $421(64.1)$ & $112(17.0)$ & $533(81.1)$ & $480(73.2)$ & $80(12.2)$ & $560(85.4)$ \\
\hline \multirow[t]{2}{*}{ Islam } & $104(15.8)$ & $20(3.0)$ & $124(18.9)$ & $84(12.8)$ & $12(1.9)$ & $96(14.6)$ \\
\hline & \multicolumn{3}{|c|}{$\chi^{2}=1.495, p>0.001$} & \multicolumn{3}{|c|}{$\chi=0.217, p>0.001$} \\
\hline \multicolumn{7}{|l|}{ Ethnicity } \\
\hline Yoruba & $495(75.3)$ & $115(17.5)$ & $610(92.8)$ & $541(82.5)$ & $81(12.3)$ & $622(94.8)$ \\
\hline Igbo & $29(4.4)$ & $8(1.2)$ & $37(5.6)$ & $19(2.9)$ & $6(0.9)$ & $25(3.8)$ \\
\hline \multirow[t]{2}{*}{ Hausa } & $1(0.2)$ & $9(1.4)$ & $10(1.5)$ & $4(0.6)$ & $5(0.8)$ & $9(1.4)$ \\
\hline & \multicolumn{3}{|c|}{$\chi^{2}=31.078^{\ddagger}, \mathrm{p}<0.001$} & \multicolumn{3}{|c|}{$\chi^{2}=15.456^{\ddagger}, p<0.001$} \\
\hline Household size & & & & & & \\
\hline$\leq 4$ & $265(40.3)$ & $93(14.2)$ & $358(54.5)$ & $338(51.5)$ & $84(12.8)$ & $422(64.3)$ \\
\hline$>4$ & $260(40.0)$ & $39(5.9)$ & $299(45.5)$ & $226(34.5)$ & $8(1.2)$ & $234(35.7)$ \\
\hline & & $=16.977, p<$ & & & 33.933, $p<0$ & \\
\hline Access to ele & & & & & & \\
\hline Yes & $360(54.8)$ & $115(17.5)$ & $475(72.3)$ & $393(60.0)$ & $86(13.1)$ & $479(73.0)$ \\
\hline No & $165(25.1)$ & $17(2.6)$ & $182(27.7)$ & $171(26.1)$ & $6(0.9)$ & $177(27.0)$ \\
\hline & & $18.122, p<$ & & & $22.736, p<0$ & \\
\hline
\end{tabular}

‡=Fisher's exact test.

Moreover, LLITN usage was observed to be significantly high among school-age children whose mothers were selfemployed. This may be attributed to self-employed mothers having more time for their children's care. This contradicts a report from another study where children of working mothers were observed to have an increased likelihood of LLITN usage [21].

The finding from this study showed that malaria prevalence in the study locations is higher than $10.6 \%$ reported in Tanzania [26] and $14 \%$ from Gambia [27] but, however, comparable with a prevalence of $17 \%$ reported by another author from Gambia [28]. The observed prevalence in this study, however, disagrees with reports from high malaria transmission areas: Uganda [2], Cote d'Ivoire [29], Rwanda [30], and Kenya [31] where higher malaria prevalence has been reported. This may be attributed to the high transmission settings of these areas. The significant association between malaria prevalence and gender is consistent with the report from Cote d'Ivoire [32] and Kenya [31] where high malaria prevalence was observed among males than females but disagrees with a report from elsewhere [26]. The low malaria prevalence observed among school-age children $>11$ years in this study is consistent with an earlier report from Côte d'Ivoire [32] but disagrees with another report from Kenya [31].

Also, the significant association between malaria prevalence and socioeconomic factors (household size, access to electricity, mother's education, and occupation) agrees with reports from other studies [20,30,31]. 


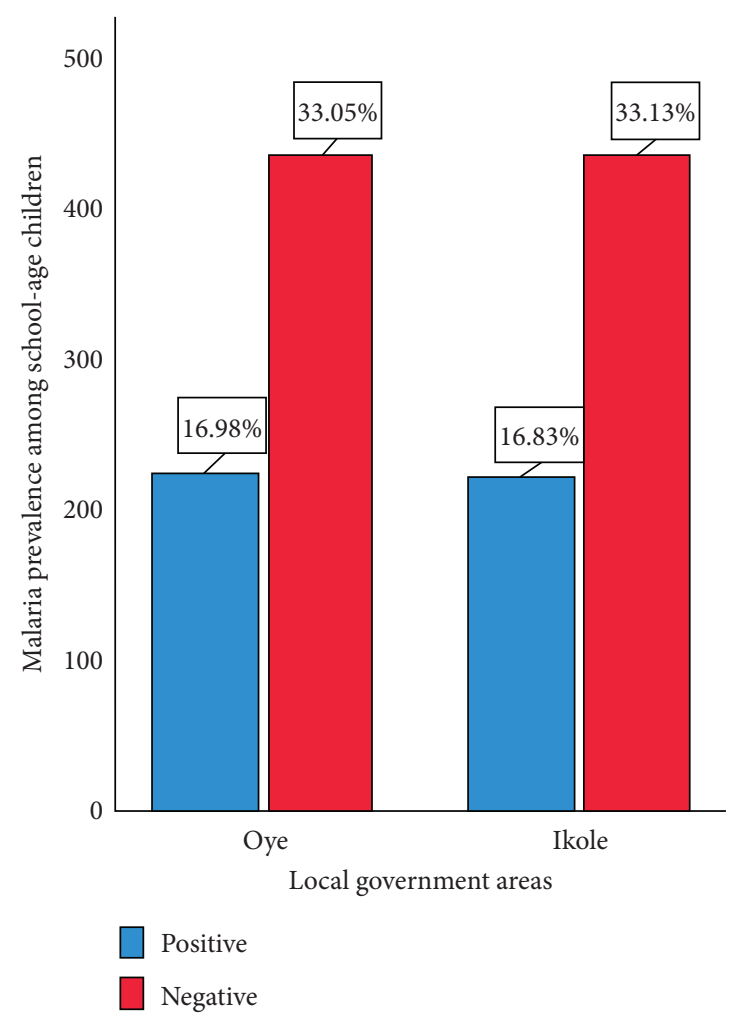

Figure 2: Malaria prevalence among respondents in Oye and Ikole LGAs.

TABLE 4: Association of sociodemographic characteristics with malaria prevalence among SAC in Oye and Ikole LGAs.

\begin{tabular}{|c|c|c|c|c|c|c|}
\hline \multirow{3}{*}{ Variables } & \multicolumn{6}{|c|}{ Malaria Prevalence } \\
\hline & \multicolumn{3}{|c|}{ Oye (\%) } & \multicolumn{3}{|c|}{ Ikole (\%) } \\
\hline & Yes $n=223$ & No $n=434$ & Total $N=657$ & Yes $n=221$ & No $n=435$ & Total $\mathrm{N}=656$ \\
\hline \multicolumn{7}{|l|}{ Age } \\
\hline $6-8$ & $75(11.4)$ & $169(25.7)$ & $244(37.1)$ & $79(12.0)$ & $167(25.5)$ & $246(37.5)$ \\
\hline $9-11$ & 89 (13.6) & $157(23.9)$ & $246(37.4)$ & $82(12.5)$ & $156(23.8)$ & $238(36.3)$ \\
\hline \multirow[t]{2}{*}{$>11$} & $59(9.0)$ & $108(16.4)$ & $167(25.4)$ & $60(9.1)$ & $112(17.1)$ & $172(26.2)$ \\
\hline & \multicolumn{3}{|c|}{$\chi^{2}=1.810, p>0.001$} & \multicolumn{3}{|c|}{$\chi^{2}=0.445, p>0.001$} \\
\hline \multicolumn{7}{|l|}{ Gender } \\
\hline Male & $124(18.9)$ & $212(32.3)$ & $336(51.1)$ & $132(20.1)$ & $219(33.4)$ & $351(53.5)$ \\
\hline Female & $99(15.1)$ & $222(33.8)$ & $321(48.9)$ & $89(13.6)$ & $216(32.9)$ & $305(46.5)$ \\
\hline & \multicolumn{3}{|c|}{$\chi^{2}=2.692, p>0.001$} & \multicolumn{3}{|c|}{$\chi^{2}=5.187, p<0.001$} \\
\hline \multicolumn{7}{|c|}{ Mother's education } \\
\hline Primary & $30(4.6)$ & $72(11.0)$ & $102(15.5)$ & $31(4.7)$ & $41(6.3)$ & $72(11.0)$ \\
\hline Secondary & $176(26.8)$ & $253(38.5)$ & $429(65.3)$ & $185(28.2)$ & $225(34.3)$ & $410(62.5)$ \\
\hline Tertiary & $17(2.6)$ & $109(16.6)$ & $126(19.2)$ & $5(0.8)$ & $169(25.8)$ & $174(26.5)$ \\
\hline & \multicolumn{3}{|c|}{$\chi^{2}=34.036, p<0.001$} & \multicolumn{3}{|c|}{$\chi^{2}=100.780, p<0.001$} \\
\hline \multicolumn{7}{|c|}{ Mother's occupation } \\
\hline Farmer & $19(2.9)$ & $50(7.6)$ & $69(10.5)$ & $6(0.9)$ & $23(3.5)$ & $29(4.4)$ \\
\hline Trader & $46(7.0)$ & $101(15.4)$ & $147(22.4)$ & $10(1.5)$ & $21(3.2)$ & $31(4.7)$ \\
\hline Self-employed & $113(17.2)$ & $141(21.5)$ & $254(38.7)$ & $205(31.3)$ & $194(29.6)$ & $399(60.8)$ \\
\hline Civil service & $39(5.9)$ & $129(19.6)$ & $168(25.6)$ & $0(0)$ & $197(30.0)$ & $197(30.0)$ \\
\hline \multirow[t]{2}{*}{ Others } & $6(0.9)$ & $13(2.0)$ & $19(2.9)$ & $0(0.0)$ & $0(0.0)$ & $0(0.0)$ \\
\hline & \multicolumn{3}{|c|}{$\chi^{2}=22.993, p<0.001$} & \multicolumn{3}{|c|}{$\chi^{2}=158.196, p<0.001$} \\
\hline \multicolumn{7}{|l|}{ Religion } \\
\hline Christianity & $183(27.9)$ & $350(53.3)$ & $533(81.1)$ & $196(29.9)$ & $364(55.5)$ & $560(85.4)$ \\
\hline \multirow[t]{2}{*}{ Islam } & $40(6.1)$ & $84(12.8)$ & $124(18.9)$ & $25(3.8)$ & $71(10.8)$ & $96(14.6)$ \\
\hline & \multicolumn{3}{|c|}{$\chi^{2}=0.193, p>0.001$} & \multicolumn{3}{|c|}{$\chi^{2}=2.944, p>0.001$} \\
\hline
\end{tabular}


TABLE 4: Continued.

\begin{tabular}{|c|c|c|c|c|c|c|}
\hline \multirow{3}{*}{ Variables } & \multicolumn{6}{|c|}{ Malaria Prevalence } \\
\hline & \multicolumn{3}{|c|}{ Oye (\%) } & \multicolumn{3}{|c|}{ Ikole (\%) } \\
\hline & Yes $n=223$ & No $n=434$ & Total $N=657$ & Yes $n=221$ & No $n=435$ & Total $\mathrm{N}=656$ \\
\hline \multicolumn{7}{|l|}{ Ethnicity } \\
\hline Yoruba & $209(31.8)$ & $401(61.0)$ & $610(92.8)$ & $211(32.2)$ & $411(62.7)$ & $622(94.8)$ \\
\hline Igbo & $10(1.5)$ & $27(4.1)$ & $37(5.6)$ & $8(1.2)$ & $17(2.6)$ & $25(3.8)$ \\
\hline \multirow[t]{2}{*}{ Hausa } & $4(0.6)$ & $6(0.9)$ & $10(1.5)$ & $2(0.3)$ & $7(1.1)$ & $9(1.4)$ \\
\hline & \multicolumn{3}{|c|}{$\chi^{2}=0.981, p>0.001$} & \multicolumn{3}{|c|}{$\chi^{2}=0.577, p>0.001$} \\
\hline \multicolumn{7}{|c|}{ Household size } \\
\hline$\leq 4$ & $182(27.7)$ & $176(26.8)$ & $358(54.5)$ & $212(32.3)$ & $210(32.0)$ & $422(64.3)$ \\
\hline$>4$ & $41(6.2)$ & $258(39.3)$ & $299(45.5)$ & $9(1.4)$ & $225(34.3)$ & $234(35.7)$ \\
\hline & \multicolumn{3}{|c|}{$\chi^{2}=100.155, p<0.001$} & \multicolumn{3}{|c|}{$\chi^{2}=145.016, p<0.001$} \\
\hline \multicolumn{7}{|c|}{ Access to electricity } \\
\hline Yes & $222(33.8)$ & $253(38.5)$ & $475(72.3)$ & $221(33.7)$ & $258(39.3)$ & $479(73,0)$ \\
\hline No & $1(0.2)$ & $181(27.6)$ & $182(27.7)$ & $0(0)$ & $177(27.0)$ & $177(27.0)$ \\
\hline & \multicolumn{3}{|c|}{$\chi^{2}=125.194, p<0.001$} & \multicolumn{3}{|c|}{$\chi^{2}=123.153, p<0.001$} \\
\hline
\end{tabular}

TABLE 5: Relationship between LLIN usage and malaria test result among respondents.

\begin{tabular}{lcccc}
\hline & \multicolumn{2}{c}{ Oye LGA } & \multicolumn{2}{c}{ Ikole LGA } \\
& Positive $(\%) N=223$ & Negative (\%) $N=434$ & Positive (\%) $N=221$ & Negative $(\%) N=435$ \\
\hline LLITN usage & & & & \\
Yes & $171(26.0)$ & $354(53.9)$ & $41(27.4)$ & $384(58.5)$ \\
No & $52(7.9)$ & $80(12.2)$ & $\chi^{2}=7.638, p<0.001$ & $51(7.8)$ \\
$p$ value & & & \\
\hline
\end{tabular}

Furthermore, the low malaria prevalence recorded in Oye and Ikole LGAs in this study may be attributed to the high usage of LLITNs observed among SAC in the study locations. This is consistent with other studies which have reported the effectiveness of net usage in the reduction of malaria cases among school-age children [15, 33-35], but this disagrees with reports from other studies $[9,36]$.

This study provides baseline information on the utilization of LLITNs among school-age children in Oye and Ikole LGAs and the impact of LLITN usage in reducing malaria infections among the study population.

\section{Limitations}

This is a cross-sectional study, which could only evaluate the association, instead of cause-and-effect relationships. LLITN usage the previous night was used as the basis to determine those who used LLITNs, and this might not be generalizable. The study was conducted in only two LGAs of Ekiti State, and therefore, the results may not be generalized to the country. The study was only based on interviews, and there were no observations conducted to validate the reported use of mosquito nets.

\section{Conclusion}

This study showed a significant association between reduction in malaria infection and usage of LLITNs among school-age children in Oye and Ikole LGAs. This observation requires continuous educations on the usage of LLITNs in the study areas to sustain malaria infection control towards total elimination.

\section{Data Availability}

The data used for this study are available from the corresponding author upon request.

\section{Conflicts of Interest}

The authors declare that they have no conflicts of interest.

\section{Acknowledgments}

The authors thank the Ministry of Health, Ekiti State, Ekiti State Primary Education Board (SPEB), Local Government Education Authority, Executive Secretaries, and Education Officers from the district education office in the LGAs who granted the approval and/or assisted the team in locating the schools. The authors also appreciate the headteachers, teachers, and parents of pupils who granted permission as well as pupils that participated in the survey. Our appreciation also goes to the interviewers for their relentless effort in accomplishing the task.

\section{References}

[1] World Health Organization, World Malaria Report 2019, World Health Organization, Geneva, Switzerland, 2019.

[2] J. Nankabirwa, S. J. Brooker, S. E. Clarke et al., "Malaria in school-age children in Africa: an increasingly important 
challenge," Tropical Medicine \& International Health, vol. 19, no. 11, pp. 1294-1309, 2014.

[3] D. D. Laishram, P. L. Sutton, N. Nanda et al., "The complexities of malaria disease manifestations with a focus on asymptomatic malaria," Malaria Journal, vol. 11, no. 1, pp. 29-32, 2012.

[4] J. A. Walldorf, L. M. Cohee, J. E. Coalson et al., "School-age children are a reservoir of malaria infection in Malawi," PLoS One, vol. 10, Article ID e0134061, 2015.

[5] A. G. Buchwald, J. A. Walldorf, L. M. Cohee et al., "Bed net use among school-age children after a universal bed net campaign in Malawi," Malaria Journal, vol. 15127 pages, 2016.

[6] D. P. Mathanga, K. E. Halliday, M. Verney et al., "The high burden of malaria in primary school children in southern Malawi," The American Journal of Tropical Medicine and Hygiene, vol. 93, no. 4, pp. 779-789, 2015.

[7] R. Ndyomugyenyi and A. Kroeger, "Using school children's reports of bed net use monitored by schoolteachers as a proxy of community coverage in malaria endemic areas of Uganda," Tropical Medicine International Health, vol. 12, pp. 230-237, 2007.

[8] C. W. Gitonga, P. N. Karanja, J. Kihara et al., "Implementing school malaria surveys in Kenya: towards a national surveillance system," Malaria Journal, vol. 9, pp. 306-308, 2010.

[9] C. Okoyo, C. Mwandawiro, J. Kihara et al., "Comparing insecticide-treated bed net use to Plasmodium falciparum infection among schoolchildren living near lake Victoria, Kenya," Malaria Journal, vol. 14, pp. 515-517, 2015.

[10] Y. Kebede, L. Abebe, G. Alemayehu et al., "Effectiveness of peer-learning assisted primary school students educating the rural community on insecticide-treated nets utilization in Jimma-zone Ethiopia," Malaria Journal, vol. 19, no. 1, pp. 1-13, 2020.

[11] F. Abamecha, M. Sudhakar, L. Abebe et al., "Effectiveness of the school-based social and behaviour change communication interventions on insecticide-treated nets utilization among primary school children in rural Ethiopia: a controlled quasiexperimental design," Malaria Journal, vol. 20, no. 1, pp. 1-15, 2021.

[12] J. U. Onwuka, J. O. Akinyemi, and I. O. Ajayi, "Household ownership and use of insecticide-treated bednets among school children in Ibadan, Oyo state, Nigeria," Malaria World Journal, vol. 7, pp. 9-13, 2016.

[13] S. S. Lim, N. Fullman, A. Stokes, N. Ravishankar, F. Masiye, and C. J. L. Murray, "Net benefits: a multicountry analysis of observational data examining associations between insecticide-treated mosquito nets and health outcomes," PLoS Medicine, vol. 8, Article ID e1001091, 2011.

[14] C. W. Gitonga, T. Edwards, P. N. Karanja, A. M. Noor, R. W. Snow, and S. J. Brooker, "Plasmodium infection, anaemia and mosquito net use among school children across different settings in Kenya," Tropical Medicine \& International Health, vol. 17, no. 7, pp. 858-870, 2012.

[15] H. Koenker, B. Munoz, M. Boulay et al., "Trends in weekly reported net use by children during and after rainy season in central Tanzania," Malaria Journal, vol. 11, pp. 218-221, 2012.

[16] A. Admasie, A. Zemba, and W. Paulos, "Insecticide-treated nets utilization and associated factors among under-5 years old children in Mirab-Abaya district, Gamo-Gofa zone, Ethiopia," Frontiers in Public Health, vol. 6, p. 7, 2018.

[17] B. Sibhatu, A. Reda, and H. Kedir, "Determinants of ownership and utilization of insecticide-treated bed nets for malaria control in Eastern Ethiopia," Journal of Tropical Medicine, vol. 2012, p. 7, Article ID 235015, 2012.
[18] M. K. Geraldine, "Factors affecting use of insecticide treated nets by children under five years of age in Kenya," American Journal of Health Research, vol. 6, no. 4, pp. 56-91, 2013.

[19] L. Sena, A. Wakgari, and A. Ali, "Predictors of long-lasting, insecticide-treated, bed net ownership and utilization: evidence from community-based cross-sectional comparative study, southwest Ethiopia," Malaria Journal, vol. 12, p. 406, 2013.

[20] J. G. Siri, "Independent associations of maternal education and household wealth with malaria risk in children," Ecology and Society, vol. 19, no. 1, 2014.

[21] M. M. Ruyange, J. Condo, C. Karema et al., "Factors associated with the non-use of insecticide-treated nets in Rwandan children," Malaria Journal, vol. 15, no. 1, pp. 355-358, 2016.

[22] A. H. Watiro and W. Awoke, "Insecticide-treated net ownership and utilization and factors that influence their use in Itang, Gambella region, Ethiopia: cross-sectional study," Risk Management and Healthcare Policy, vol. 9, p. 101, 2016.

[23] D. Souleymane, T. Druetz, E. Bonnet et al., "Insecticidetreated nets ownership and utilization among under-five children following the 2010 mass distribution in Burkina Faso," Malaria Journal, vol. 13, p. 353, 2014.

[24] T. Fürst, G. Raso, C. A. Acka, A. B. Tschannen, E. K. N’Goran, and J. Utzinger, "Dynamics of socioeconomic risk factors for neglected tropical diseases and malaria in an armed conflict," PLoS Neglected Tropical Diseases, vol. 3, no. 9, p. e513, 2009.

[25] A. L. García-Basteiro, C. Schwabe, C. Aragon et al., "Determinants of bed net use in children under five and household bed net ownership on Bioko Island, Equatorial Guinea," Malaria Journal, vol. 10, no. 1, p. 179, 2011.

[26] L. E. Mboera, V. M. Bwana, S. F. Rumisha et al., "Malaria, anaemia and nutritional status among schoolchildren in relation to ecosystems, livelihoods and health systems in Kilosa district in central Tanzania," Biomedical Central Public Health, vol. 15, no. 1, p. 553, 2015.

[27] E. N. Takem, M. Affara, A. Amambua-Ngwa et al., "Detecting foci of malaria transmission with school surveys: a pilot study in the Gambia," PLoS One, vol. 8, Article ID e67108, 2013.

[28] A. R. Oduro, D. J. Conway, D. Schellenberg et al., "Seroepidemiological and parasitological evaluation of the heterogeneity of malaria infection in the Gambia," Malaria Journal, vol. 12, no. 1, p. 222, 2013.

[29] S. B. Assi, M. C. Henry, C. Rogier et al., "Inland rice production systems and malaria infection and disease in the forest region of western Cote d'Ivoire," Malaria Journal, vol. 12, no. 1, p. 233, 2013.

[30] K. C. Sifft, D. Geus, C. Mukampunga et al., "Asymptomatic only at first sight: malaria infection among schoolchildren in highland Rwanda," Malaria Journal, vol. 15, no. 1, p. 553, 2016.

[31] S. Kepha, B. Nikolay, F. Nuwaha et al., "Plasmodium falciparum parasitaemia and clinical malaria among school children living in a high transmission setting in western Kenya," Malaria Journal, vol. 15, no. 1, p. 157, 2016.

[32] C. A. Houngbedji, B. N. Prisca, E. Hürlimann et al., "Disparities of Plasmodium falciparum infection, malaria-related morbidity and access to malaria prevention and treatment among school-aged children: a national cross-sectional survey in Côte d'Ivoire," Malaria Journal, vol. 14, no. 1, 2015.

[33] D. A. Larsen, P. Anglewicz, J. Bennett, T. P. Eisele, J. Yukich, and P. Hutchinson, "Community coverage with insecticidetreated mosquito nets and observed associations with allcause child mortality and malaria parasite infections," The 
American Journal of Tropical Medicine and Hygiene, vol. 91, no. 5, pp. 950-958, 2014.

[34] J. Pinchoff, L. Simubali, E. Colantuoni et al., "Factors associated with sustained use of long-lasting insecticide-treated nets following a reduction in malaria transmission in southern Zambia," The American Journal of Tropical Medicine and Hygiene, vol. 93, no. 5, pp. 954-960, 2015.

[35] D. W. Oguttu, J. K. Matovu, D. C. Okumu et al., "Rapid reduction of malaria following introduction of vector control interventions in Tororo district, Uganda: a descriptive study," Malaria Journal, vol. 16, no. 1, pp. 1-8, 2017.

[36] T. Leenstra, D. H. Rosen, B. L. Nahlen et al., "Permethrintreated bed nets in the prevention of malaria and anemia in adolescent schoolgirls in western Kenya," The American Journal of Tropical Medicine and Hygiene, vol. 68, no. 4_suppl, pp. 86-93, 2003. 